\title{
Orientation program for transition of newly recruited nurses to the psychiatric setting
}

\author{
Huiting Xie*, Lei Liu, Jia Wang
}

\begin{abstract}
Xie H, Liu L, Wang J. Orientation program for transition of newly recruited nurses to the psychiatric setting. Curr Res Integr Med 2018;3(1):1-6.

BACKGROUND: Transition of nurses towards readiness for practice has been increasingly gaining attention from many organizations, because it is closely associated with retention challenges and competency requirements. Though structured orientation programs are conducted by many organizations, literatures examining the effectiveness of such programs on transition into practice for newly recruited nurses are limited.
\end{abstract}

METHOD: This study employed a descriptive, pre-test, post-test design. 30 registered and enrolled nurses engaged in an orientation program comprising of 1-day program that acquaints new staff with the organization and 3 other days relating to mental health within the first month of their employment.

In today's rapidly changing healthcare setting, nurses are expected to acquire theoretical foundations of nursing practice, technical skills and performance behaviours necessary for their role in caring for patients with complex problems (1). For nurses who are newly recruited into the workforce, a difficult period of stress, shock and acceptance often awaits them (2-4). A common assumption made by many with regards to undergraduate nursing internship practice is that, it develops nurses who are ready to assume the role of professional nurse (5). Often, even though the newly recruited nurses have achieved the educational and legal requirements to enter nursing practice, a "mismatch" or "gap" has commonly been used to describe the lack of preparation of these nurses to assume practice. Many of them lack exposure to certain clinical skills and the experience needed to engage in effective nursing practice. The adjustment of newly recruited nurses into the professional nursing role is further burdened by escalating levels of patient acuity and nursing workload (6). They may also lack the practice expertise and the confidence required to navigate within a highly dynamic and intense clinical environment (6).

Increasing efforts are been made towards helping new nurses become practice ready, for their readiness is closely associated with retention challenges and competency requirements (7). The inability of new nurses to properly transit into the role of professional nurses may bring about grave consequences. Newly recruited nurses may be forced out of the nursing profession which is already plagued by severe manpower crunch. Fewer nurses to meet the daily needs of hospitalized patients and lower staffing levels continue to be linked to a higher incidence of adverse outcomes. In addition, poor transition of newly recruited nurses into practice may also increase the risks of practice errors or lapses in patients' safety (8). Hence, there is a need for nurses who just began their nursing career to transit into the work environment quickly in order to provide safe care for patients with complex care needs (9).

Nurse educators are faced with the challenge of preparing newly recruited nurses to develop the full range of skills they need to be ready to assume the role of the professional nurse (1). In order to develop registered nurses during an era of nursing shortages, orientation programs can be provided to facilitate the retention of new nurses and the transition of newly recruited nurses into nursing practice $(10,11)$. Though nurse residency programs are available, these are typically focused on nursing skills development without much information on the organization (12). Locally, residency programs are reserved for the purpose of upskilling existing nurses within the organization into new roles as opposed to preparing newly recruited nurses to fulfil nursing roles.
Pre-test and post-test data were collected on the Casey-Fink Readiness for Practice Survey and TCM Employee Commitment Survey.

RESULTS: Participant's readiness and commitment were generally high to begin with and improved after the orientation program. Participants were uncomfortable when asked to perform venipuncture. The same sign of uneasiness was observed during and after the orientation program when participating nurses were asked to respond to emergencies.

CONCLUSION: This study contributes to the knowledge base regarding the important aspects of orientation programs and the outcomes relating to nurses' transition to professional practice.

Key Words: Orientation program; Nurses; Psychiatric setting

\section{Significance of study}

Many organizations have a structured way of preparing the newly recruited staff for practice through orientation programs (13). Though studies from both the educational and healthcare industries demonstrated positive outcomes following orientation programs $(14,15)$, studies examining the impact of orientation program on newly recruited nurses' readiness for practice and organizational commitment are limited. Yet, the cost of orientation can be high, ranging from $\$ 20,000$ to $\$ 50,000$, so it is financially important to assess the commitment of nurses following the attendance of orientation programs (16). A formalized evaluation of the orientation program will assist nursing administrators to determine if the needs of newly recruited nurses are met and assist educators in the preparation of the newly appointed nurses for practice (17). Hence, this study aims to evaluate the effectiveness of an orientation program on practice readiness and employee's commitment to the organization.

\section{Theoretical framework}

The orientation program employed in this study is guided by the selfefficacy theory. Self-efficacy can be mitigated by four information sources namely, vicarious experience, mastery performance, verbal persuasions, and physiologic feedback (18-23). Information sources for the development of self-efficacy are inherent in the orientation program. During the orientation program, newly recruited nurses had the opportunity to observe and model their behaviours against that of the experienced nurses. This was referred to by Bandura, as vicarious experience; it provides opportunities for socialization into the role of a professional nurse thus enacting mastery performance. The facilitators of the program offered verbal persuasion by providing immediate feedback to the new nurses and suggested changes to enhance practice. The orientation program also assisted the newly recruited nurses to understand the demands and expectations placed on a fully functional nurse. This in turn could alter physiologic feedback by decreasing the amount of role conflicts and resulting anxiety that occurs during the transition. Thus, with the orientation program, efficacy outcomes such as the new nurses' capabilities to produce designated levels of performance could be developed. In this study, the outcome is represented by the readiness of the newly recruited nurses to transit to nursing practice and their organizational commitment in this study.

Institute of Mental Health, Singapore

Correspondence: Dr. Huiting Xie, Institute of Mental Health, Singapore-539747, Telephone- 656389 2522, email-hui_ting_xie@imh.com.sg

Received: November 6, 2017, Accepted: December 29, 2017, Published: January 05, 2018 


\section{METHODS}

This study utilized a descriptive design which employed a single group pre-test, post-test design set in a major public mental health institution in Singapore. All eligible, newly recruited nurses during a 6 months study period were invited to participate in the study. Eligible participants included those who were: [1] registered and enrolled nurses within their first month of employment as nurses at the institution, [2] nurses within 21 to 55 years of age and [3] nurses with the ability to understand English, the language through which the orientation program was delivered. This study excluded nurses who were yet to be registered with the Nursing Board, were not employed full time or who had just returned from a qualification upgrade, because their shortened or prior work experience with the organization could have an impact on their commitment to the organization. To attain a more holistic overview on the impact of orientation program on newly recruited nurses and with the focus on organizational commitment, both newly licensed nurses and those with prior nursing experience before joining the organization were included in the study. Information on their prior nursing experience would be captured. With a population of 30 nurses estimated from recruitment numbers over six months based on data in previous years from the study site and a response distribution of $50 \%$ which produce estimates for a larger sample size, a sample size of 28 was recommended to produce a $95 \%$ confidence interval with five percent margin of error. A consensus sample of 30 nurses was recruited.

\section{Intervention}

In this study, participants engaged in a 4 days orientation program guided by both the self-efficacy theory and prior empirical evidence which suggests that orientation program can bring about positive outcomes. The 4 days orientation program consisted of 1-day in-house program that acquainted new staff with the organization. This was followed by another 3 days where participants learned about mental health nursing, that aimed at facilitating their transition from newly recruited staff to practicing nurses. Unlike most new employee orientation programs, that focuses primarily on the organization and code of conduct for employees, this program was nursing specific and include modules such as role socialization, safety, communication and specialty contents inspired by the literature and utilized within the transition to practice model by the National Council of State Boards of Nursing (NCSBN) in many American states (24). Though the orientation program's duration and depth of the modules covered differed from that of NCSBN, it was designed based on the needs of the study site with the input and approval from the management team.

\section{Instruments}

Casey-Fink Readiness for Practice Survey: The Casey-Fink Readiness for Practice Survey in 2008 (CFRP) measured nurses' perceived readiness for practice (25). It is a 20 -item survey rated on a 4 -point likert scale ( $1=$ strongly disagree; 4=strongly agree). Higher score indicates greater readiness for practice. Its content was validated using an expert consensus development process. In addition, construct validity was established after initial exploratory factor analysis (EFA) on a sample of 162 participants found 4 factors which formed the CFRP's subscales, namely: [1] Clinical Problem Solving, [2] Learning Techniques, [3] Professional Identity and [4] Trials and Tribulations. Following which, confirmatory factor analysis (CFA) was conducted to revalidate the EFA findings in a second, independent sample of 267 participants (25). The model fit of all items in the instrument was acceptable, Comparative Fit Index $(\mathrm{CFI})=0.86$ and Root Mean Square Error of Approximation (RMSEA) $=0.06$. Cronbach alphas for the subscales was 0.80 (Clinical Problem Solving), 0.50 (Learning Techniques), 0.65 (Professional Identity) and 0.63 (Trials and Tribulations). The Cronbach alpha for the entire scale is 0.69 , though not ideal, it is acceptable for use in research (26-28).

TCM Employee Commitment Survey: The TCM Employee Commitment Survey (ECS) is a 22-item measure rated on a 7-point Likert scale ( $1=$ strongly disagree, $7=$ strongly agree) (26). This instrument includes three well-validated scales, the Affective Commitment Scale (ACS), the Normative Commitment Scale (NCS) and the Continuance Commitment Scale (CCS) (26). Three forms of employee commitment to an organization were measured, namely: [1] desire-based (affective commitment), [2] obligation-based (normative commitment) and [3] cost-based (continuance commitment). Employees with a strong affective commitment have an intrinsic desire to stay with the organization (because they want to). Those with strong normative commitment stay because they feel they ought to while those with strong continuance commitment stay because they have to do so. After reverse scoring for selective items in the instrument, scores were summed to yield an overall score for each of the three domains of commitment where higher score indicates greater commitment.

\section{Demographic survey}

In addition, a self-designed questionnaire was also administered to capture demographic characteristics of the participants including their designation, nurses' age, gender, race, religion, educational level, marital status and educational level. Data on participants' prior experience in nursing and mental health nursing was also captured.

Participants completed all self-administered instruments before undertaking the orientation program. The administration of the questionnaire took approximately 15-30 minutes. Upon completion of the orientation program (post-test), the same set of questionnaires, except the demographic survey, was administered to identify changes in nurses' perceived readiness for practice and commitment to the organization.

\section{Data analysis}

The data was analysed using Statistical Package for the Social Science (SPSS) version $19.0 \alpha=0.05$ was used for all analysis (27). Descriptive data on participants' characteristics and inferential information of outcomes following orientation program were made.

\section{Ethical considerations}

As per the study site's requirement, ethical approval was obtained from both the study site and the institution review board of the healthcare group overseeing the study site before the commencement of the study. Voluntary consent was obtained from every participant with all of them being aware that they have the freedom to withdraw at any point in time.

\section{RESULTS}

\section{Participants' characteristics}

A summary of the participants' characteristics is shown in Table 1. A total of 30 nurses completed the orientation program as well as the pre- and post-test measures, yielding a response rate of $100 \%$. The mean age of the participants was 28.33 years $(S D=7.69)$. The majority of the participants are female, newly recruited registered nurses, who have degree or diploma qualifications. Their mean years of experience in nursing at 5.7 years $(S D=5.96)$ could be potentially affecting the results but their prior experience in mental health nursing was much lower at 9 months ( $\mathrm{SD}=2.06$ years), limiting the impact of prior years of experience in adapting to mental health setting.

\section{TABLE 1}

\section{Participants characteristics}

\begin{tabular}{ccccc}
\hline Demographics & N & Min, Max & Mean & SD \\
\hline Designation & 30 & - & - & - \\
Registered Nurse & 17 & - & - & - \\
$\begin{array}{c}\text { Enrolled/ Assistant } \\
\text { Nurse }\end{array}$ & 13 & - & - & 7.685 \\
\hline Age (Years) & 30 & 20,48 & 28.33 & - \\
\hline Gender & $29^{a}$ & - & - & - \\
\hline Male & 7 & - & - & - \\
Female & 22 & - & - & - \\
Race & $27^{a}$ & - & - & - \\
\hline Chinese & 4 & - & - & - \\
Malay & 6 & - & - & - \\
Indian & 5 & - & - & - \\
Filipino & 4 & - & - & - \\
Myanmar/ Burmese \\
$\begin{array}{c}\text { Others (Boyanese } \\
\text { Javanese, Batak) }\end{array}$ & 5 & 3 & - & - \\
\hline
\end{tabular}




\begin{tabular}{ccccc}
\hline Religion & 30 & - & - & - \\
\hline Buddhism & 9 & - & - & - \\
Islam & 9 & - & - & - \\
Christianity & 8 & - & - & - \\
Hinduism & 1 & - & - & - \\
Free-thinker & 3 & - & - & - \\
\hline Educational Level & 30 & - & - & - \\
\hline Institute of Technical & 4 & - & - & - \\
Education & 13 & - & - & - \\
Diploma & 13 & - & - & - \\
Degree & 30 & - & - & - \\
\hline Marital Status & 21 & - & - & - \\
\hline $\begin{array}{c}\text { Single } \\
\text { Married }\end{array}$ & 9 & - & - & - \\
Years of Experience in & 30 & 0,19 & 5.7 & 5.9576 \\
Nursing & 30 & 0,7 & 0.741 & 2.0642 \\
\hline $\begin{array}{l}\text { Years of Experience in } \\
\text { Mental Health Nursing }\end{array}$ & 30 & & & \\
\hline NOTE: a-Variables with missing data & &
\end{tabular}

TABLE 2

Participants' organizational commitment before and after the orientation program

\begin{tabular}{|c|c|c|c|c|c|c|}
\hline $\begin{array}{c}\text { Scale } \\
\text { (Possible } \\
\text { range) }\end{array}$ & $\begin{array}{l}\text { (Mean } \\
\text { Score) }\end{array}$ & SD & $\begin{array}{l}\text { Cronbach } \\
\text { Alpha }\end{array}$ & $\mathbf{t}$ & df & $\mathbf{p}$ \\
\hline \multicolumn{3}{|c|}{$\begin{array}{l}\text { TCM Employee Commitment (22- } \\
\text { 154) }\end{array}$} & - & 3.203 & 29 & 0.003 \\
\hline Pre-test & $105.70(4.80)$ & 13.05 & 0.71 & - & - & - \\
\hline Post-test & $111.73(5.08)$ & 16.96 & 0.87 & - & - & - \\
\hline \multicolumn{7}{|c|}{ TCM Employee Commitment- Subscale } \\
\hline \multicolumn{2}{|c|}{ Affective (8-56) } & - & - & 2.05 & 29 & 0.05 \\
\hline Pre-test & $40.07(5.01)$ & 4.76 & 0.34 & - & - & - \\
\hline Post-test & $42.23(5.28)$ & 5.84 & 0.71 & - & - & - \\
\hline \multicolumn{2}{|c|}{ Continuance (8-56) } & - & - & -1.18 & 29 & 0.25 \\
\hline Pre-test & $35.50(4.44)$ & - & - & - & - & - \\
\hline Post-test & $36.77(4.60)$ & 6.56 & 0.53 & - & - & - \\
\hline \multicolumn{2}{|c|}{ Normative (6-42) } & 7.5 & 0.69 & 2.917 & 29 & 0.007 \\
\hline Pre-test & $30.13(5.02)$ & 5.99 & 0.69 & - & - & - \\
\hline Post-test & $32.73(5.46)$ & 6.71 & 0.86 & - & - & - \\
\hline
\end{tabular}

NOTE: Possible range of scores for each scale is denoted in the parentheses. ${ }^{b}$ Mean score for each item on the scale is denoted in the 428 parentheses (i.e. mean total divided by number of items in the scale). Each item is assessed on a 7-points Likert scale, with 1=strongly 429 disagree and 7=strongly agree.

As seen in Table 2, the internal consistency of participants' responses to the TCM Employee Commitment Survey (ECS), utilized to measure participants' organizational commitment, was assessed by computing the Cronbach's alpha. Moderate to high internal consistency was demonstrated for participants' responses to overall ECS score 0.71(Pre-test) and 0.87 (Post-test). Participants' responses to the ECS suggested that they joined the organization thinking that they are somewhat committed to the organization, achieving an overall organizational commitment score of approximately 105 within a possible range of 22 to 154 . After undertaking the orientation program, their overall organizational commitment rose significantly from pre-test $(\mathrm{M}=105.70, \mathrm{SD}=13.05)$ to post-test $(\mathrm{M}=111.73, \mathrm{SD}=16.96), \mathrm{t}(29)=$. $3.203, p=0.003$. The change in their affective and normative commitment improved significantly following the orientation program, suggesting that they have improved intrinsic desire (want to) and obligation to (ought to) remain in the organization that provided them with the orientation program. While their continuance commitment (commitment to the organization due to cost they have spent) also improved following the orientation program, the difference was not statistically significant.

\section{TABLE 3}

Nurses' readiness for practice before and after the orientation program

\begin{tabular}{|c|c|c|c|c|c|c|}
\hline $\begin{array}{l}\text { Scale (Possible } \\
\text { range of scores) }\end{array}$ & $\begin{array}{c}\text { Mean Total } \\
\text { (Mean Score) }^{\mathrm{b}}\end{array}$ & SD & Cronbach's & $\mathbf{t}$ & df & p \\
\hline \multicolumn{3}{|c|}{ Readiness for Practice (20-80) } & - & -0.58 & 29 & 0.57 \\
\hline Pre-test & $60.40(3.02)$ & 6.38 & 0.88 & - & - & - \\
\hline Post-test & $60.90(3.05)$ & 4.44 & 0.8 & - & - & - \\
\hline \multicolumn{7}{|c|}{ Readiness for Practice - Subscale } \\
\hline \multicolumn{3}{|c|}{ Clinical Problem Solving (7-28) } & - & 0.46 & 29 & 0.65 \\
\hline Pre-test & $21.23(3.03)$ & 2.69 & 0.79 & - & - & - \\
\hline Post-test & $21.43(3.06)$ & 2.14 & 0.79 & - & - & - \\
\hline \multicolumn{3}{|c|}{ Learning Techniques (2-8) } & - & 1.37 & 29 & 0.18 \\
\hline Pre-test & $5.73(2.87)$ & 0.97 & - & - & - & - \\
\hline Post-test & $5.97(2.99)$ & 0.765 & - & - & - & - \\
\hline \multicolumn{3}{|c|}{ Professional Identity (5-20) } & - & 0.86 & 29 & 0.4 \\
\hline Pre-test & $16.17(3.23)$ & 1.91 & 0.67 & - & - & - \\
\hline Post-test & $15.90(3.18)$ & 1.77 & 0.73 & - & - & - \\
\hline \multicolumn{3}{|c|}{ Trials and Tribulations (6-24) } & & 0.96 & 29 & 0.34 \\
\hline Pre-test & $17.27(2.88)$ & 2.1 & 0.62 & - & - & - \\
\hline Post-test & $17.60(2.93)$ & 1.22 & 0.15 & - & - & - \\
\hline
\end{tabular}

NOTE: a Possible range of scores for each scale is denoted in the parentheses. ${ }^{b}$ Mean score for each item on the scale is denoted in the parentheses (i.e. mean total divided by number of items in the scale). Each item is assessed on a 4-point Likert scale, with $1=$ strongly disagree and $4=$ strongly agree.

As seen in Table 3, moderate to high internal consistency was shown in participants' responses to the Casey-Fink Readiness for Practice Survey@ 2008 (CFRP), utilized to measure participants' readiness for practice. Their responses to CFRP indicated that their overall readiness for practice was high to begin with. They attained scores of 60 plus with scores of 80 being the highest possible scores. A series of paired-samples t-test was conducted to evaluate the readiness for practice and commitment of newly recruited nurse before and after attending the orientation program. No statistical significant difference was found in participants' overall readiness for practice, $t(29)=$ $0.576, p=0.569$.

However, other than their readiness to assume the professional identity of nursing where their mean score for the subscale dropped from 16.17 to 15.90 after the orientation program, participants' readiness to solve clinical problems (from mean score of 21.23 to 21.43), apply learning techniques (from mean score of 5.73 to 5.97 ) and overcoming trials and tribulations (from mean score of 17.27 to 17.60 ) all improved following the orientation program. Participants' characteristics and readiness for practice and organizational commitment (Tables 4-6).

\section{TABLE 4}

Bivariate correlation between participants' age, years of nursing experience, years of experience in mental health nursing, readiness for practice and organizational commitment

\begin{tabular}{|c|c|c|c|c|c|c|c|c|}
\hline $\begin{array}{l}\text { S. } \\
\text { No. }\end{array}$ & Variables & 1 & 2 & 3 & 4 & 5 & 6 & 7 \\
\hline 1 & Age & - & - & - & - & - & - & - \\
\hline 2 & $\begin{array}{c}\text { Years of Experience in } \\
\text { Nursing }\end{array}$ & $0.94^{* *}$ & - & - & - & - & - & - \\
\hline 3 & $\begin{array}{l}\text { Years of Experience in } \\
\text { Mental Health Nursing }\end{array}$ & $0.64^{* *}$ & $0.57^{\star *}$ & - & - & - & - & - \\
\hline 4 & $\begin{array}{l}\text { Readiness for } \\
\text { Practice(Pre) }\end{array}$ & 0.13 & 0.1 & 0.17 & - & - & - & - \\
\hline 5 & $\begin{array}{l}\text { Readiness for } \\
\text { Practice(Post) }\end{array}$ & 0.03 & 0.02 & 0.2 & $0.67^{\star *}$ & - & - & - \\
\hline 6 & $\begin{array}{c}\text { Organizational } \\
\text { Commitment (Pre) }\end{array}$ & 0.33 & 0.28 & 0.31 & $0.51^{* *}$ & $0.46^{*}$ & - & - \\
\hline 7 & $\begin{array}{c}\text { Organizational } \\
\text { Commitment (Post) }\end{array}$ & 0.24 & 0.25 & 0.21 & 0.46 & $0.53^{\star *}$ & $0.79^{* *}$ & - \\
\hline \multicolumn{9}{|c|}{ Note: ${ }^{*} p \leq 0.05 .{ }^{* *} p \leq 0.01$} \\
\hline
\end{tabular}

The relationship between participants' age, years of experience in both nursing and mental health nursing with readiness for practice and organizational commitment was investigated using a bivariate Pearson correlation. No statistical significant differences were found between participants' readiness for practice and organizational commitment both before and after the orientation program (Table 4). Readiness for practice 
and organizational commitment was also closely associated. Increment in readiness for practice influence organizational commitment positively and significantly, $\mathrm{p}<0.01$ (Table 4).

\section{TABLE 5}

One-way ANOVA between participants' demographics and readiness for practice

\begin{tabular}{|c|c|c|c|c|c|c|c|c|c|}
\hline \multicolumn{2}{|c|}{ Demographic } & \multicolumn{4}{|c|}{$\begin{array}{l}\text { Readiness for Practice } \\
\text { (Pre) }\end{array}$} & \multicolumn{4}{|c|}{$\begin{array}{l}\text { Readiness for Practice } \\
\text { (Pre) }\end{array}$} \\
\hline Variables & $\mathrm{N}$ & $M$ & SD & $T / F$ & $p$ & $M$ & SD & $\mathrm{T} / \mathrm{F}$ & $p$ \\
\hline Designation & 30 & 60.4 & 6.38 & 1.24 & 0.23 & 60.9 & 4.44 & 1.98 & 00 \\
\hline Regis & 17 & 61.65 & 7.25 & & & 62.24 & 4.64 & & \\
\hline \multicolumn{10}{|c|}{ Nurse } \\
\hline $\begin{array}{l}\text { Assistant/ } \\
\text { Enrolled }\end{array}$ & 13 & 58.77 & 4.8 & - & - & 59.15 & 3.6 & - & - \\
\hline \multicolumn{10}{|c|}{ Nurse } \\
\hline Gender & $29^{a}$ & 60.66 & 6.33 & 1.5 & 0.15 & 60.93 & 4.51 & 0.91 & 0.37 \\
\hline Male & 7 & 63.71 & 7.02 & - & - & 62.29 & 4.75 & - & - \\
\hline Female & 22 & 59.68 & 5.94 & - & - & 60.5 & 4.46 & 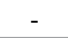 & . \\
\hline Race & $27^{a}$ & 61.15 & 6.23 & 2.15 & 0.1 & 61.26 & 4.5 & 0.66 & 0.66 \\
\hline Chinese & 4 & 62 & 4.69 & - & - & 61.5 & 5.69 & - & 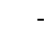 \\
\hline Malay & 6 & 58.83 & 3.06 & - & - & 59.67 & 2.16 & - & 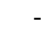 \\
\hline Indian & 5 & 59.2 & 3.77 & - & - & 59.6 & 2.19 & - & \\
\hline Filipino & 4 & 66.5 & 8.58 & - & - & 64.25 & 7.59 & - & \\
\hline $\begin{array}{l}\text { Myanmar/ } \\
\text { Burmese }\end{array}$ & 5 & 64.6 & 6.73 & - & - & 62.4 & 5.68 & - & \\
\hline Others & 3 & 55 & 6.93 & - & - & 61 & 2.65 & - & \\
\hline Religion & 30 & 60.4 & 6.38 & 1.03 & 0.42 & 60.9 & 4.44 & 1.4 & 0.26 \\
\hline Buddhism & 9 & 60.44 & 7.28 & - & - & 60.44 & 4.77 & - & 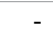 \\
\hline Islam & 9 & 57.67 & 4.69 & - & - & 60.33 & 2.35 & - & 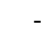 \\
\hline Christianity & 5 & 64.8 & 8.32 & - & - & 64.6 & 5.07 & - & - \\
\hline Catholic & 3 & 60.67 & 4.04 & - & - & 58 & 3.46 & - & 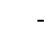 \\
\hline Hinduism & 1 & 55 & - & - & - & 56 & - & - & - \\
\hline Others & 3 & 62.67 & 5.51 & - & - & 62.33 & 6.66 & - & - \\
\hline Education & 30 & 60.4 & 6.38 & 3.83 & $0.03^{*}$ & 60.9 & 4.44 & 2.07 & 0.19 \\
\hline ITE & 4 & 57.75 & 3.2 & - & - & 59 & 2.94 & - & - \\
\hline Diploma & 13 & 57.85 & 4.69 & - & -- & 59.46 & 2.18 & - & 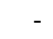 \\
\hline Degree & 13 & 63.77 & 7.21 & - & & 62.92 & 5.72 & - & - \\
\hline Marital Status & 30 & 60.4 & 6.38 & -0.96 & 0.35 & 60.9 & 4.44 & 0.81 & 0.4 \\
\hline Single & 21 & 59.67 & 5.87 & - & - & 61.33 & 4.45 & - & - \\
\hline Married & 9 & 62.11 & 7.52 & - & - & 59.89 & 4.48 & - & \\
\hline
\end{tabular}

NOTE: ${ }^{a}$ Variables with missing data.

${ }^{b}$ Other race includes Boyanese, Javanese, Batak.

'Levene's test for homogeneity of variances was significant, Welch F-ratio was reported * $p \leq 0.05$.

A series of independent-samples t-test and one-way analysis of variance (ANOVA) were also conducted to explore nurses' demographics (designation, gender, race, religion, education, and marital status) with readiness for practice and commitment to the organization (Tables 5 and 6). Their education was shown to significantly influence readiness for practice at pre-test, before the undertaking of orientation program, $F(2,27)=3.82$, $\mathrm{p}=0.03$. Post-hoc comparison using the Tukey Honest Significant Difference test indicated only a statistical significant difference between nurses with a diploma qualification $(\mathrm{M}=57.85, \mathrm{SD}=4.69)$ and nurses with a degree qualification $(\mathrm{M}=63.77, \mathrm{SD}=7.21) \quad$ (Table 5). However, participants' demographic characteristics did not affect their organizational commitment both at pre-test and post-test.

Similarly, their education also significantly influence their organizational commitment at pre-test, $F(2.19)=3.88, p=0.04$. Participants with a degree qualification $(M 105.91, S D=10.59)$ had significantly higher organizational commitment at pre-test than those with a diploma qualification $(\mathrm{M}=94.00$, $\mathrm{SD}=10.22$ ) according to post-hoc comparison using the Tukey Honest Significant Difference test (Table 6).

TABLE 6

One-way ANOVA between participants' demographics and organizational commitment

\begin{tabular}{rlllllllll} 
Demographic & \multicolumn{3}{c}{$\begin{array}{c}\text { Organizational } \\
\text { (Pre) }\end{array}$} & Commitment & $\begin{array}{c}\text { Organizational } \\
\text { (Post) }\end{array}$ & Commitment \\
\hline N & $M$ & SD & T/F & $p$ & $M$ & SD & T/F & $p$
\end{tabular}

\begin{tabular}{|c|c|c|c|c|c|c|c|c|c|}
\hline Designation & 30 & 105.7 & 13.05 & 0.11 & 0.91 & 111.73 & 16.96 & 0.1 & 0.92 \\
\hline Registered & 17 & 105.94 & 15.99 & - & - & 112 & 19.91 & - & - \\
\hline \multicolumn{10}{|c|}{ Nurse } \\
\hline $\begin{array}{l}\text { Assistant/ } \\
\text { Enrolled }\end{array}$ & 13 & 105.38 & 8.39 & - & - & 111.38 & 12.91 & - & - \\
\hline \multicolumn{10}{|c|}{ Nurse } \\
\hline Gender & $29^{a}$ & 105.27 & 13.07 & 0.73 & 0.47 & 111.03 & 16.82 & 0.45 & 0.66 \\
\hline Male & 7 & 108.43 & 10.69 & - & - & 113.57 & 12.59 & - & - \\
\hline Female & 22 & 104.27 & 13.81 & - & - & 110.23 & 18.14 & - & - \\
\hline Race & $27^{a}$ & 105.59 & 13.4 & 2.2 & 0.09 & 111.11 & 17.44 & 2.12 & 0.1 \\
\hline Chinese & 4 & 107.75 & 8.42 & - & -- & 104.75 & 15.24 & - & - \\
\hline Malay & 6 & 94.67 & 13.68 & - & & 100.83 & 21.19 & - & - \\
\hline Indian & 5 & 106 & 12.81 & - & - & 120.8 & 14.13 & - & - \\
\hline Filipino & 4 & 112.25 & 8.06 & - & - & 121.75 & 13 & - & - \\
\hline $\begin{array}{c}\text { Myanmar/ } \\
\text { Burmese }\end{array}$ & 5 & 115.8 & 16.12 & - & - & 119 & 14.97 & - & - \\
\hline Others & 3 & 98 & 3.61 & - & - & 96.67 & 7.51 & - & - \\
\hline Religion & 30 & 105.7 & 13.05 & 0.9 & 0.5 & 111.73 & 16.96 & 0.79 & 0.57 \\
\hline Buddhism & 9 & 112.11 & 13.53 & - & - & 116.67 & 13.43 & - & - \\
\hline Islam & 9 & 99 & 14.52 & - & - & 104.67 & 22.71 & - & - \\
\hline Christianity & 5 & 105 & 14.05 & - & - & 120.4 & 13.78 & - & - \\
\hline Catholic & 3 & 106.33 & 2.08 & - & - & 111.33 & 8.5 & - & \\
\hline Hinduism & 1 & 106 & - & - & - & 108 & - & - & - \\
\hline Others & 3 & 107 & 10.15 & - & - & 105.33 & 18.61 & - & - \\
\hline Education & 30 & 105.7 & 13.05 & 3.17 & 0.06 & 111.73 & 16.96 & 1.93 & 0.17 \\
\hline ITE & 4 & 102 & 2.83 & - & - & 109 & 6.63 & - & - \\
\hline Diploma & 13 & 100.46 & 13.26 & - & - & 105.92 & 19.99 & - & - \\
\hline Degree & 13 & 112.08 & 12.46 & - & - & 118.38 & 14.06 & - & - \\
\hline $\begin{array}{l}\text { Marital } \\
\text { Status }\end{array}$ & 30 & 105.7 & 13.05 & -1.09 & 0.28 & 111.73 & 16.96 & -0.38 & 0.71 \\
\hline Single & 21 & 104 & 12.19 & - & - & 110.95 & 17.97 & - & - \\
\hline Married & 9 & 109.67 & 14.85 & - & - & 113.56 & 15.2 & - & - \\
\hline
\end{tabular}

NOTE: a Variables with missing data

${ }^{b}$ Other race includes Boyanese, Javanese, Batak

Skills nurses were uncomfortable performing

Participants were asked to indicate nursing skills that they were uncomfortable performing. Before the orientation program, participants indicated over a frequency of 91 times of skills they were uncomfortable performing. After the orientation program, the frequency dropped to 80 .

The top three skills identified by the nurses among various skills as the most uncomfortable performing were venepuncture, responding to emergency and EKG/Telemetry. These were consistent before and after the orientation program. However, participants became more uncomfortable in responding to emergencies after the orientation program, unlike most other skills with which they were generally more comfortable following the orientation program (Table 7).

\section{TABLE 7}

Number of nurses re 451 porting the skills they were most uncomfortable performing

\begin{tabular}{cccccc}
\hline Skills & \multicolumn{2}{c}{$\begin{array}{c}\text { Pre - Most } \\
\text { uncomfortable }\end{array}$} & \multicolumn{2}{c}{$\begin{array}{c}\text { Post - Most } \\
\text { uncomfortable }\end{array}$} & $\begin{array}{c}\text { Trend between pre- } \\
\text { test and post-test }\end{array}$ \\
\hline & $\begin{array}{c}\text { Top 3 } \\
\text { skills }\end{array}$ & $\begin{array}{c}\text { Ranked } \\
1 \text { st }^{\mathrm{a}}\end{array}$ & $\begin{array}{c}\text { Top 3 } \\
\text { skills }\end{array}$ & $\begin{array}{c}\text { Ranked } \\
1 \mathrm{st}^{\mathrm{a}}\end{array}$ & \\
\hline $\begin{array}{c}\text { Venipuncture } \\
\text { Responding to an }\end{array}$ & 14 & 9 & 9 & 3 & $\downarrow$ \\
$\begin{array}{c}\text { emergency/ CODE/ } \\
\text { changing patient } \\
\text { condition }\end{array}$ & 12 & 8 & 16 & 11 & $\uparrow$ \\
\hline
\end{tabular}




\begin{tabular}{|c|c|c|c|c|c|}
\hline $\begin{array}{c}\text { EKG/ Telemetry } \\
\text { monitoring and } \\
\text { interpretation }\end{array}$ & 12 & 5 & 10 & 5 & $\downarrow$ \\
\hline Chest tube care & 9 & 3 & 8 & 3 & $\downarrow$ \\
\hline $\begin{array}{l}\text { Bladder catheter } \\
\text { insertion/irrigation }\end{array}$ & 7 & 4 & 6 & 3 & $\downarrow$ \\
\hline $\begin{array}{l}\text { Central line care } \\
\text { (dressing change, } \\
\text { blood draws, } \\
\text { discontinuing) }\end{array}$ & 6 & 2 & 5 & 2 & $\downarrow$ \\
\hline $\begin{array}{l}\text { IV pumps/ PCA } \\
\text { pump operation }\end{array}$ & 6 & 1 & 3 & 1 & $\downarrow$ \\
\hline $\begin{array}{c}\text { Charting/ } \\
\text { documentation }\end{array}$ & 5 & 3 & 2 & 1 & $\downarrow$ \\
\hline Giving verbal report & 5 & 1 & 4 & 1 & $\downarrow$ \\
\hline $\begin{array}{l}\text { Medication } \\
\text { administration }\end{array}$ & 3 & 2 & 2 & 1 & $\downarrow$ \\
\hline Assessment skills & 4 & 1 & 2 & 1 & $\downarrow$ \\
\hline $\begin{array}{l}\text { Intravenous (IV) } \\
\text { administration }\end{array}$ & 2 & 1 & 1 & 1 & $\downarrow$ \\
\hline $\begin{array}{l}\text { NG tube/ Dobhoff } \\
\text { care }\end{array}$ & 2 & 1 & 0 & 0 & $\downarrow$ \\
\hline Pulse oximetry & 2 & 1 & 3 & 1 & - \\
\hline $\begin{array}{l}\text { Wound care/ } \\
\text { dressing change/ } \\
\text { wound vac }\end{array}$ & 2 & 1 & 1 & 0 & $\downarrow$ \\
\hline $\begin{array}{l}\text { Blood glucose } \\
\text { monitoring device }\end{array}$ & 2 & 1 & 1 & 0 & $\downarrow$ \\
\hline $\begin{array}{l}\text { Intravenous (IV) } \\
\text { starts }\end{array}$ & 1 & 1 & 1 & 1 & - \\
\hline $\begin{array}{l}\text { Trach care/ } \\
\text { suctioning }\end{array}$ & 1 & 1 & 2 & 0 & $\uparrow$ \\
\hline Total & 91 & - & 80 & - & - \\
\hline
\end{tabular}

\section{DISCUSSION}

The significant difference found on the overall TCM Employee Commitment scale suggests the effectiveness of the orientation program in enhancing organizational commitment. The orientation program could play a role in instilling commitment to the organization, possibly contributing to the retention of staff. Further analysis of the scores on the subscales revealed that the average score for individual item was lowest in the continuance subscale across pre-test and post-test. This suggests that nurses were not burden by the cost of leaving the organisation. Organizations however would be impacted by the costs spent in training a newly recruited nurse when the nurse left the organization before contributing back to the organization. Therefore, this has implications for the organisation administrators on improving the policies, benefits and programs for the staffs so as to increase retention of nurses.

Moreover, nurses' readiness for practice and organizational commitment were closely linked as shown by its statistically significant correlation. According to the research, formalized evaluation of the orientation program will assist nursing administrators to determine if the needs of newly recruited nurses are met and assist educators in the preparation of the newly appointed nurses for practice. In terms of nurses' readiness for practice, though the findings revealed no statistically significant differences in nurses' readiness before and after the orientation program, their overall readiness score increased after the orientation program. It was reported that there is a clear connection between a well-resourced and relevant orientation program with improved retention rates and greater staff satisfaction (18).

Their readiness to assume the professional identity of nursing was the only area where instead of improving after the orientation program, their readiness decreased. The orientation program may have given them a clearer perspective of their role expectations that led to their apprehension in assuming the professional identity of nursing, hence the decrease in readiness.

Nevertheless, across both pre-test and post-test, the mean score for each item on the scale Readiness for Practice have showed that participants scored highest on the Professional Identity Subscale, and the lowest on the Trials and Tribulations Subscale. This suggested that nurses found pride in their status as nurses, which could signal that nurses valued their role and take responsibility in providing optimal care for patients. However, the lowest score on the Trials and Tribulations subscales appeared to suggest that nurses perceived themselves as inadequate to handle the trials and tribulations when they assumed the professional identity of nursing. Hence, more guidance and training is needed for nurses to better perform nursing tasks in a similar fashion to that of a professional nurse. Future orientation program could be tailored to address this area of concern.

Analysis of the demographic variables with nurses' readiness for practice revealed only significant differences in the educational level of nurses on readiness for practice and organizational commitment at pre-test. Specifically, nurses with degree qualifications rated higher commitment when they first entered the organization at pre-test. This difference, however, was no longer significant at post-test, suggesting that the orientation program was effective in preparing nurses with other qualifications for practice and enhancing commitment, as shown by the increment in readiness for practice and organisational commitment scores from pre-test and post-test. According to researchers, a well thought out orientation program can reduce adjustment periods for novice nurses, minimize turnover and establish a solid foundation for a productive and lengthy career (19). Aside from education, other participants' characteristics was not shown to influence participants' readiness and organizational commitment suggesting that other change could be attributed to the undertaking of the orientation program as opposed to their demographic characterises.

\section{Limitation/recommendation for future study}

This study was conducted in a naturalistic setting hence many factors such as prior nursing experience that may affect readiness for practice and organizational commitment were measured but not controlled for. Due to limitation of funding period and small projected number of recruitment, only 30 newly recruited nurses participated in the study. Though these were limitations, prior studies evaluating orientation program for residents were published also with sample sizes of 10,12 and 20 respectively (20-22).

As the orientation program was usually conducted in 4 consecutive days rather intensively, the learners may be overwhelmed with vast information, but their understanding of concepts were not fully tested, and the application of knowledge was not closely followed up in the clinical settings. An alternative for other researchers who may be interested in carrying out further study will be to spread the 4-days program over a reasonable period of time, e.g. 3 months to allow the learners to apply what they have learnt after each class and come back to continue on the next module after one month. By doing this, the learners will not be overloaded with too much information at a time and they will also have time to appreciate what they have learnt. Nevertheless, this study provides preliminary information about the changes in nurses' state of readiness for practice and commitment to the organization within the 4 days interval. With a prolonged study period, the changes in readiness for practice and organizational commitment could be resulting from more varied factors such as salary and benefits, as opposed to the orientation program itself.

Knowledge and skills learnt in the orientation program are meant to guide learners and to be applied in clinical settings. Researchers can further work with ward supervisors and nurse educators for follow up, after the orientation program is completed, in order to have a better understanding of the effectiveness of the program and to fine-tune it for better outcome if the need arise.

\section{CONCLUSION}

Orientation programs have the potential to develop good communications with the newly recruited nurses, to introduce organizational goals, policies and procedures, to convey responsibilities and expectations clearly and to provide the newly recruited nurses with information that will ease the transition into practice and enhance commitment. In this study, both nurse's commitment to the organization and their readiness to practice changed for the better following a brief 4 days orientation program, with the impact on organizational commitment stronger than the latter. The provision of orientation programs can facilitate the acculturation of employees into the organization with the potential of preparing new nurses for their professional role follow up, after the orientation program is completed, in order to have a better understanding of the effectiveness of the program and to fine-tune it for better outcome if the need arise.

\section{ACKNOWLEDGEMENT}

This study was conducted with the support, expertise and guidance from the XXX. The study was supported by the XXX grant. 


\section{REFERENCES}

1. Klein CJ. Linking competency-based assessment to successful clinical practice. J Nurs Educ. 2006;45:379-83.

2. Casey K, Fink RM, Krugman M, et al. The graduate nurse experience. J Nurs Adm. 2004;34:303-11

3. Halfer D, Graf E. Graduate nurse perceptions of the work experience. Nurs Econ. 2006;24:150-155.

4. Ross H, Clifford K. Research as a catalyst for change: The transition from student to Registered Nurse. J Clin Nurs. 2002;11:545-53.

5. Gaberson $\mathrm{KB}$, Oermann $\mathrm{MH}$. Clinical teaching strategies in nursing 2007;2nd ed

6. Duchscher J. A process of becoming: The stages of new nursing graduate professional role transition. J Contin Educ Nurs. 2008;39:441-50.

7. Dyess SM, Sherman RO. The first year of practice: New graduate nurses' transition and learning needs. J Contin Educ Nurs. 2009;40:403-10.

8. National Council of State Boards of Nursing. Transition to Practice. 2015.

9. Etheridge SA. Learning to think like a nurse: Stories from new nurse graduates. J Contin Educ Nurs. 2007;38:24-30.

10. Asselin ME, Parker EB. Unit orientation for experienced nurses. Process and evaluation, J Nurs Staff Dev. 1991;7:126-29

11. Delaney C. Walking a fine line: Graduate nurses' transition experiences during orientation. J Nurs Educ. 2003;42:437-43.

12. Welding NM. Creating a nursing residency: Decrease turnover and increase clinical competence. Adv Prac. 2011;20:37-40.

13. Park M, Jones CB. A retention strategy for newly graduated nurses: An integrative review of orientation programs, J Nurses Staff Dev. 2010;26:142-49.

14. Klein HJ, Weaver NA. The effectiveness of an organizational level orientation training program in the socialization of new hires. Personal Psych. 2000;53:47-66.
15. Grover M, Puczynski S. Residency orientation: What we present and its effect on our residents. Fam Med. 1999;31:697-02.

16. Burns P, Poster EC. Competency development in new Registered Nurse graduates: Closing the gap between education and practice. J Contin Educ Nurs. 2008;39: 67-73.

17. Meyer R, Meyer M. Utilization-focused evaluation: Evaluating the effectiveness of a hospital nursing orientation program. J Nurses Staff Dev. 2000;16:202-06.

18. Fey M, Miltner RS. A competency based orientation program for new graduate nurses. J Nurs Adm. 2000;30:126-32.

19. Marcum E, West R. Structured orientation for new graduates: A retention strategy. J Nurses Staff Dev. 2004;20:118-24.

20. Duff P. An orientation program for new residents in obstetrics and gynaecology. Obstet Gynecol. 1994;83:473-75.

21. Nielsen PE, Holland RH, Foglia LM. Evaluation of a clinical skills orientation program for residents. Am J Obstet Gynecol. 2003;189: 858-60.

22. Pandya J, Bhagwat S, Kini S. Evaluation of clinical skills for first-year surgical residents using orientation programme and objective structured clinical evaluation as a tool of assessment. J Postgrad Med. 2010;56:297-300.

23. Bandura A. Self-efficacy: towards a unifying theory of behavioural change. Psychol Rev. 1977;84:191-215.

24. Spector N, Echternacht M. A regulatory model for transitioning newly licensed nurses to practice. J Nurs Regul. 2010;1:18-25.

25. Casey K, Fink R, Jaynes C, et al. Readiness for practice: the senior practicum experience. J Nurs Educ. 2011;50:646-52.

26. Herscovitch L, Meyer J. Commitment to organizational change: Extension of a three-component model. J Appl Psychol. 2002;87:474-87.

27. IBM Corp. Released. IBM SPSS Statistics for Windows, Version 19.0. Armonk, NY: IBM Corp. 2010

28. Peterson RA. A meta-analysis of Cronbach's coefficient alpha. J Consum Res. 1994;21:381-91. 